\title{
A HERMENEUTICA REFLEXIVA COMO ELEMENTO TEÓRICO LEGITIMIDADOR DA JUSTIÇA SÓCIO-AMBIENTAL: ANALISE DO CASO NO STJ DA QUEIMA DA CANA DA AÇUCAR
}

\author{
THE REFLECTIVE HERMENEUTICS AS SOCIAL AND EVIRONMENTAL \\ JUSTICES THEORIC LEGITIMIZER: CASE ANALYSIS IN THE STJ ABOUT \\ BURNING OF SUGAR CANE
}

\author{
${ }^{1}$ Fernando Amaral \\ ${ }^{2}$ Liane Francisca Hüning Pazinato
}

\section{RESUMO}

Trata o presente artigo em dimensionar teoricamente a postura reflexiva do órgão jurisdicional e seu reflexo dentro de determinadas tradições jurídicas teóricas e a consequiente efetivação do direito fundamental ecologicamente equilibrado. Assim, mister enfrentar a dimensão da cidadania ecológica, dos danos ambientais e da justiça sócio-ambiental assim como a posição as principais correntes e teorias do direito que se ocuparam em delimitar a posição do juiz diante do direito. Ocupou-se, também, por demonstrar a posição de Hans George Gadamer dentro da hermenêutica filosófica descritiva bem como eventual polêmica com a dialética prescritiva de Junger Habermas, bem como a relação de complementariedade de ambas e formar, assim, uma hermenêutica reflexiva. Para contextualizar as tradições jurídicas apresentadas e a necessidade de reflexão sobre o contexto posto em julgamento, foi apresentado um estudo de caso sobre a divergência existente na autorização da queima da cana-de-açúcar na jurisprudência do Superior Tribunal de Justiça, sua influencia na fundamentação e na compreensão reflexiva do julgador, bem como identificar no discurso a tradição teórica e a influência destes fatores no julgamento. Se utilizou da pesquisa bibliográfica e jurisprudencial. O resultado alcançado foi a necessidade de um circulo hermenêutico reflexivo conduzindo-o a uma justiça ambiental e efetivação da cidadania ecológica, concluindo que os preconceitos e a reflexão sobre o contexto normativo apresentado são fundamentais para se diminuir os danos ambientais consubstanciando uma hermenêutica reflexiva numa perspectiva inclusiva da hermenêutica e da dialética como legimadoras de uma teoria jurídica emancipadora.

Palavras-chave: Hermenêutica, Teoria do direito, Justiça sócio-ambiental

\footnotetext{
${ }^{1}$ Mestre em Direito e Justiça Social pela Universidade Federal do Rio Grande - FURG, Rio Grande do Sul (Brasil). Professor efetivo na Universidade Federal do Rio Grande - FURG, Rio Grande do Sul (Brasil). E-mail: nandoamaral@gmail.com

${ }^{2}$ Doutora em Direito pela Pontifícia Universidade Católica do Rio Grande do Sul - PUC/RS, Rio Grande do Sul (Brasil). Professora da Universidade Federal do Rio Grande - FURG, Rio Grande do Sul (Brasil). E-mail: lianehuning@gmail.com
} 


\begin{abstract}
This article intends to dimension theoretically the courts reflective posture and its reflection within certain theoretical legal traditions and the consequent realization of ecologically balanced fundamental right. So, it is necessary to face the dimension of ecological citizenship, environmental damage and social and environmental justice as well as the position and the mainstream theories of law that is occupied in defining the judge's position in front of the Law. Minded, too, to demonstrate Hans George Gadamers position within the descriptive philosophical hermeneutics as well as eventual polemic with the dialectic prescriptive of Junger Habermas and the complementary relationship of both and thereby form a reflective hermeneutics. To contextualize the presented legal traditions and the need to reflect about the context put on judgment, a case study was presented about the divergence in authorizing the sugar cane burning in the case law of the Supreme Court, its influence in the grounds and reflective understanding of the judge, as well as identifying in the discourse the theoretical tradition and the influence of these factors in the trial. We used the literature and case law research. The result achieved was the need for a hermeneutic circle reflective leading him to an environmental justice and realization of ecological citizenship, concluding that prejudice and reflection on the presented normative context are key to reduce environmental damage evidencing a reflexive hermeneutic perspective inclusive of hermeneutics and dialectics as legitimizers of an emancipatory legal theory.
\end{abstract}

Keywords: Hermeneutics, Legal theory, Social and environmental justice 


\section{INTRODUÇÃO}

O presente artigo tem por escopo investigar a descrição ontológica gadameriana do circulo da compreensão, a influencia da prescrição dialética habermasiana neste processo e a necessidade deste procedimento na realização da justiça sócio-ambiental.

O desenvolvimento do artigo está estruturado em quatro partes.

A primeira parte se ocupou de demonstrar a evolução geracional dos direitos do homem, iniciando na cidadania civil e fechando na cidadania existencial ecológica bem como a necessária conexão com a perspectiva do dano e da justiça sócio-ambiental.

A segunda parte ocupou-se por demonstrar a posição de Hans George Gadamer na descrição do circulo hermenêutico em sua hermenêutica filosófica e sua importância para a interpretação, bem como eventual polêmica com a prescrição dialética de Junger Habermas.

A terceira parte momento deu-se atenção em descrever as principais teorias do direito que tratam do poder de atuação do juiz diante de um texto normativo. Foi abordado as tradições da Escola Histórica do Direito, da Jurisprudência dos conceitos, do Movimento para o Direito Livre, da Jurisprudência dos Interesses, da Jurisprudência dos valores e da Teoria Pura do Direito.

Uma estudo de caso, na quarta parte, foi utilizado para ilustrar casuisticamente os aportes teóricos da parte dois e três para demonstrar a diferença de proteção dada ao macrobem meio ambiente. Portanto, partindo desta necessidade se utilizou de um caso, a queima da cana de açúcar na jurisprudência do Superior Tribunal de Justiça, para demonstrar se uma hermenêutica filosófica reflexiva favorece a cidadania ecológica através de uma justiça mitigadora dos danos ambientais no caso concreto nos termos aqui propostos e assim, esperemos, contribuir com este estudo na doutrina brasileira.

\section{A EVOLUÇÃO DOS DIREITOS DO HOMEM. DA CIDADANIA CIVIL A CIDADANIA ECOLÓGICA}

Sendo o direito a um ambiente ecologicamente equilibrado um dos "direitos do homem" eles merecem especial atenção do Estado ${ }^{1}$ devido a sua fundamentalidade existencial

\footnotetext{
${ }^{1}$ Toda constituição democrática, representa um embate político que resulta numa conquista, seja a conformação do Estado Liberal (direitos de liberdade), seja a do Estado Social de bem estar (direitos de igualdade) que correspondem as formações clássicas de Estado. Segundo Anderson Orestes Cavalcante Lobato (O reconhecimento e as garantias constitucionais dos direitos fundamentais. Cadernos de Direito Constitucional
} 
do indivíduo e por estarem estritamente ligados com outros temas fundamentais. Nestes termos Bobbio (2004, p. 1) destaca que há uma relação de existência entre direitos do homem, democracia e paz. Para este autor italiano só há democracia numa sociedade de cidadãos, e estes, só existem, no sentido jurídico da palavra, quando lhe são reconhecidos alguns direitos fundamentais.

\section{Com base nesta historicidade Bobbio revelou uma classificação geracional ${ }^{2}$ de}

e Ciência Política. São Paulo: Ed. RT, n. 22, p. 141-159, 1998.1998, p. 2), a constitucionalização dos direitos do homem acompanhou a mudança de concepção de Estado de direito. A conformação deste Estado, portanto, se dá com a evolução dos direitos do homem obrigando o Estado ora a se abster, ora a prover através da previsão de direitos fundamentais nas Constituições. O Estado liberal surge como resultado da luta contra o Estado Absolutista, e para garantir a liberdade (não intervenção estatal) dos cidadãos insere dois princípios nas constituições: a separação dos poderes - como meio assecuratório de controle entre eles - e o reconhecimento dos direitos civis. A Declaração dos Direitos do Homem (1791) foi muita clara ao rezar que "toda sociedade que não assegura a garantia dos direitos nem a separação de poderes não possui constituição". Dentro destes direitos individuais esta a ampla liberdade de contratar e, como desdobramento, a não intervenção do Estado no mercado. O Estado só interviria para garantir as regras naturais do mercado. Após a primeira guerra mundial verificou-se a insuficiência da ampla liberdade econômica pois a livre atuação dos agentes econômicos no mercado acabou gerando graves problemas sociais. O Estado social surge como reação a esta não intervenção estatal perniciosa pois a liberdade irrestrita acabou gerando desigualdades sociais e necessitava-se buscar um bem estar humanitário. Assim, num primeiro momento se amplia o catálogo de direitos fundamentais incluindo direitos de ordem social, econômica e culturais para após oferecer os meios necessários para tanto Paulo Bonavides (BONAVIDES, Paulo. Do Estado Liberal ao Estado Social. São Paulo: Malheiros, 2013, p. 186) faz uma diferenciação entre Estado Social e Estado Socialista. Num primeiro momento, como reação ao liberalismo nocivo, surge o Estado social que seria a garantia de direitos sociais mínimos e a intervenção indireta na economia não mais para garantir o mercado, mas para regulá-lo. No Estado socialista, total ou parcial, para eliminar o capitalismo ele começa a monopolizar certas atividades econômicas ou concorrer nelas com a iniciativa privada, intervindo diretamente na economia. Eros Grau (GRAU, Eros Roberto. A ordem econômica da constituição de 1988. São Paulo: Malheiros, $12^{a}$. Ed. 2007. p. 148) chama estas intervenções do Estado na economia, respectivamente, de absorção ou participação onde o Estado é um agente econômico que detém os meios de produção. Falar de Estado é falar de Constituição (pois não existe Estado fora de uma ordem constitucional), e falar de constituição é falar do seu conteúdo material principal: direitos fundamentais. Portanto, é intima a relação entre direitos do homem e Estado. Diante do direito fundamental a um ambiente ecologicamente equilibrado há também um Estado de Direito ambiental que "pode ser compreendido como produto de novas reivindicações fundamentais do ser humano e particularizado pela ênfase que confere a proteção do meio ambiente" (LEITE, José Rubens Morato. AYALA, Patryck de Araújo. Dano ambiental: do individual ao coletivo extrapatrimonial. Teoria e prática. 6. ed. São Paulo: Revista dos Tribunais, 2014, p. 43).

2

constitucionalismo latino americano a teoria geracional de Norberto Bobbio deve ser ressalvada. Conforme já afirmamos é intima a relação entre direitos do homem e Estado (O reconhecimento e as garantias constitucionais dos direitos fundamentais. Cadernos de Direito Constitucional e Ciência Política. São Paulo: Ed. RT, n. 22, p. 141159, 1998.1998, p. 2). Portanto devido as ditaduras e conseqüentes sincopes democráticas no Brasil, observação que serve para os regimes autoritários da historia da américa latina, se teve uma solução de continuidade nos direitos políticos. Um olhar histórico para os textos constitucionais brasileiros, os que nos interessa, temos que os direitos civis (primeira geração de direitos, cidadania civil) surgiram em parte com a Constituição Imperial de 1824; os direitos sociais (segunda geração de direitos, cidadania social) com a Constituição de 1934; os direitos políticos (primeira geração de direitos, cidadania política) com a Constituição de 1934 suprimido com a Carta de 1937, restabelecido com a Constituição de 1946, suprimido com a Carta de

1967 e restabelecido na Constituição de 1988 junto com os direitos difusos (terceira geração de direitos). Como se percebe a nossa peculiaridade histórica na evolução dos Direitos Fundamentais, e seu reflexo no Estado e na cidadania, está em que adotando dicotomia geração/dimensão os nossos direitos políticos, além da inversão histórica proposta por Bobbio, tiveram uma geração em 1934, finda em 1937, uma geração em 1946, finda em 1967 e se tornou uma dimensão, junto com os demais horizontes de direitos, com a Constituição de 1988. Devido às ditaduras, e valorizando a força normativa e a historicidade dos direitos fundamentais, temos no Brasil temos a seguinte cronologia cidadã: 1- direitos civis (primeira dimensão, cidadania civil, desde 1824); 2 - direitos sociais (segunda dimensão, cidadania social, desde 1934) e; 3 - direitos políticos e difusos (terceira dimensão, desde 1988). 
direitos do homem ${ }^{3}$. Os de primeira geração (civis e políticos), os de segunda geração (direitos sociais), os de terceira geração que dentre eles o mais importante, segundo este autor italiano, é o de viver num ambiente não poluído ${ }^{4}$.

Sob a perspectiva dos poderes e deveres do Estado em relação a estes direitos, para Norberto Bobbio (ibidem, p. 6) embora as exigências de direitos possam estar dispostas cronologicamente em diversas fases ou gerações, suas espécies são sempre duas com relação aos poderes constituídos: ou impedir os malefícios de tais poderes ou obter seus benefícios. Os de primeira geração, correspondem os direitos de liberdade, ou um não-agir do Estado; os de segundo, os direitos sociais, uma ação positiva do Estado; nos direitos de terceira e de quarta geração, podem existir direitos tanto de uma quanto de outra espécie .

Portanto, temos que direitos do homem são dimensões que surgem através da historia dos povos que vão aumentando o nível de cidadania do homem e que é dever do Estado, através dos seus Poderes, que emanam do povo (pois não!), não incidir na proibição da proteção deficiente bem como no retrocesso social. Portanto, os direitos do homem é, em ultima analise, a realização da cidadania ${ }^{5}$.

Como as cidadanias (direitos do homem) ainda continuam em plena evolução e a cidadania ecológica, que segundo Bobbio, é a reivindicação mais importante dos direitos de terceira geração (ibidem, p. 5), esta também está dentro deste processo de surgimento de novos direitos. De acordo com Birnfeld a cidadania ecológica é composta por ações $e$ abstenções destinadas a manter a incolumidade dos fatores da natureza que contribuem para a manutenção da vida (2006, p. 11).

\footnotetext{
${ }^{3}$ Este surgimento de novos direitos se dá através da historicidade social que, segundo Norberto Bobbio (A era dos direitos. tradução de Carlos Nelson Coutinho, Rio de Janeiro: Elsevier, 2004, p. 63), ocorreu de três modos: a) porque aumentou a quantidade de bens considerados merecedores de tutela; b) porque foi estendida a titularidade de alguns direitos típicos a sujeitos diversos do homem; c) porque o próprio homem não é mais considerado como ente genérico, ou homem em abstrato, mas é visto na especificidade ou na concreticidade de suas diversas maneiras de ser em sociedade, como criança, velho, doente, etc.

4 Norberto Bobbio destaca que se está ainda em constante evolução e cita os direitos de quarta geração advindo das reivindicações dos direitos do homem em relação a pesquisa biológica (2004, p. 5).

${ }^{5}$ Com base nesta perspectiva cidadã - direito de ter direitos -, Marshal já em um texto de 1949 (MARSHAL, T.

H. Cidadania, classe social e status. Trad. Meton Porto Gadelha. Rio de Janeiro: Zahar, 1963, p. 63) propôs uma tipologia: a) cidadania civil - que englobaria os direitos necessários a liberdade individual - ir e vir, imprensa, pensamento e fé, propriedade e conclusão de contratos válidos, justiça igual, etc.; b) cidadania política

- que englobaria o direito de participar no exercício do poder político; c) cidadania social - que englobaria tudo o que vai desde o direito a um mínimo de bem-estar econômico e segurança ao direito de participar, por completo na herança social e levar a vida de um ser civilizado de acordo com os padrões que prevalecem na sociedade. Consolidando as gerações de direito de Bobbio e as cidadanias de Marshal temos que os direitos de primeiro geração contem a cidadania civil e política e os de segunda geração a cidadania social. Os direitos de terceira, segundo o autor italiano, por ter uma heterogeneidade e vagueza muito grande carece de um lócus cidadão mais definido.
} 
É devido a especialidade deste direito do homem-cidadão que não se poder ficar apegado a critérios tradicionais de analise ordinária do dano. A proteção valorativa deste macrobem jurídico especial necessita de um olhar especifico. Por este motivo compartilhamos com José Rubens Morato Leite e Patryck de Araújo Ayala (2014. p. 98) que:

\begin{abstract}
dano ambiental significa, em uma primeira acepção, uma alteração indesejável ao conjunto de elementos chamados meio ambiente, como, por exemplo, a poluição atmosférica; seria, assim, a lesão ao direito fundamental que todos têm de gozar e aproveitar do meio ambiente apropriado. Contudo, em sua segunda conceituação, dano ambiental engloba os efeitos que esta modificação gera na saúde das pessoas e em seus interesses.
\end{abstract}

Da mesma forma, diante desta interdependência ${ }^{6}$ com a saúde, a justiça em casos ambientais deve-se livrar de amarras interpretativas literais. A justiça sócio-ambiental para ser efetiva necessita de outros horizontes, pois ela é:

\begin{abstract}
"conjunto de princípios e práticas que: - asseguram que nenhum grupo social, seja ele étnico, racial ou de classe, suporte uma parcela desproporcional das consequências ambientais negativas de operações econômicas, decisões de políticas e programas federais, estaduais, locais, assim como da ausência ou omissão de tais políticas; asseguram acesso justo e equitativo, direto e indireto, aos recursos ambientais do país; - asseguram amplo acesso às informações relevantes sobre o uso dos recursos ambientais, a destinação de rejeitos e a localização de fontes de riscos ambientais, bem como processos democráticos e participativos na definição de políticas, planos, programas e projetos que lhes dizem respeito; - favorecem a constituição de sujeitos coletivos de direitos, movimentos sociais e organizações populares para serem protagonistas na construção de modelos alternativos de desenvolvimento que assegurem a democratização do acesso aos recursos ambientais e a sustentabilidade do seu uso." (ACSELRAD, Henri; MELLO, Cecília Campello do Amaral; BEZERRA, Gustavo das Neves, 2009, p. 41).
\end{abstract}

Por isso que hodiernamente entende-se por injustiça ambiental um dando que lesa o mais vulnerável na relação ecológica, pois ela acaba sendo:

\footnotetext{
6 Sobre a interdependência da cidadania ecológica com o direito tributário, Liane Franscica Hüning Birnfeld destaca que "todo o direito tributário deve ter seu conteúdo não apenas para adequar, mas também concretizar os direitos fundamentais, pois na forma que ressalta Oliveira, deve-se ter por pressuposto que os direitos de terceira dimensão - dentre os quais destaca-se a defesa do meio ambiente - são adicionados à composição plena dos direitos fundamentais que do ordenamento jurídico constitucional. Esses direitos compõem o conjunto delineador das facetas do Estado, bem como o conjunto de princípios e diretrizes que direcionam sua atuação frente à sociedade e seus interesses" (BIRNFELD. Liane Francisca Hüning. A extrafiscalidade nos impostos brasileiros como instrumento jurídico-econômico de defesa do meio ambiente ecologicamente equilibrado 2013. 299 f. Tese (Doutorado) - Faculdade de Direito, Pontifícia Universidade Católica do Rio Grando (sic) Sul, Porto Alegre, 2013, p. 111).
} 
o mecanismo pelo qual sociedades desiguais, do ponto de vista econômico e social, destinam a maior carga dos danos ambientais do desenvolvimento às populações de baixa renda, aos grupos raciais discriminados, aos povos étnicos tradicionais, aos bairros operários, às populações marginalizadas e vulneráveis. (ibidem, p. 41).

Diante do perfil cidadania ontologicamente existencial e social da cidadania ecológica é que o juiz e o cientista do direito necessitam de uma hermenêutica jurídica e uma teoria do direito que tutele eficientemente este bem jurídico evitando, assim, o retrocesso social bem como a realização da justiça sócio-ambiental.

\section{A (POLÊMICA ENTRE A) HERMENÊUTICA DE GADAMER E A DIALÉTICA DE HABERMAS}

Diante da necessidade de um horizonte adequado do interprete sobre o meio ambiente, cumpre destacar o modo como se opera a compreensão, interpretação e aplicação dos textos jurídicos e eventual conflito entre a hermenêutica e a dialética.

Quanto à estrutura da interpretação coube a filosofia-hermenêutica trazer fundamentos que até hoje não teve uma oposição seria. Consolidada pelo alemão Martin Heidegger este tratou da precompreensao do intérprete como fator primordial para uma correta compreensão dos fatos. Hans-George Gadamer, como base em Heidegger, trouxe esta estrutura interpretativa em sua clássica obra Verdade e Método lançada em 1960 para a hermenêutica jurídica tornando-se o principal teórico da hermeneutica-filósofica.

Gadamer adverte que a compreensão dos textos se torna legítima quando a précompreensao do intérprete não é arbitraria, o intérprete não pode manipular os preconceitos para extrair da norma o sentido que lhe aprouver, neste termos:

\footnotetext{
A compreensão somente alcança sua verdadeira possibilidade, quando as opiniões prévias, com as quais ela inicia, não são arbitrárias. Por isso faz sentido que o intérprete não se dirija aos textos diretamente, a partir da opinião prévia que lhe subjaz, mas que examine tais opiniões quanto à sua legitimação, isto é, quanto à sua origem e validez (GADAMER, 2014, p. 356).
}

Ou seja, a compreensão somente é válida quando o intérprete não se utiliza de subterfúgios argumentativos para forjar a interpretação. Logo, deve o hermeneuta estar aberto aos (pre)conceitos cabíveis para extrair o sentido do texto.

Outro destaque que se deve fazer é que para Gadamer nao há possibilidade de cindir interpretação da compreensão. Estes atos são ontologicamente únicos pois: 


\begin{abstract}
A interpretaçao não é um ato posterior e ocasionalmente complementar a compreensão. Antes comprender é sempre interpretrar, e, por conseguinte a interpretação é forma explicita da compreensão (ibidem, p. 406).
\end{abstract}

Gadamer avança e afirma que quem interpreta também aplica a norma: “Ora, nossas reflexões nos levaram a admitir que, na compreensão, sempre ocorre algo com uma aplicação do texto a situação atual do interprete" (ibidem, p. 406).

Outros pontos fundamentais da teoria hermenêutica de Gadamer na estrutura da interpretação está quanto a tradição, fusão de horizontes e preconceitos do interprete (que não necessariamente são nocivos, é no sentido de conceitos prévios). Nas palavras de Gadamer, "horizonte é o âmbito de visão que abarca e encerra tudo o que é visível a partir de um determinado ponto" (idem, p. 399). O autor complementa:

(...) o horizonte do passado, do qual vive toda vida humana e que se apresenta sob a forma de tradição, que já esta sempre em movimento. (...) O nosso próprio passado a qual se volta consciência histórica, faz parte do horizonte móvel a partir do qual vive a vida humana, esse horizonte que a determina como origem e tradição. Compreender uma tradição, sem duvida, requer uma tradição histórica. (ibidem, pp 402-403, sem grifos no original)

Ainda,

(...) uma situação hermenêutica está determinada pelos preconceitos que trazemos conosco. Estes formam o horizonte de um presente, pois representam aquilo alem do que não conseguimos ver. (...) O horizonte do presente pois não se forma a margem do passado que trazemos conosco. Não existe um horizonte do presente por is mesmo, assim como não existem horizontes a margem do passado. Antes, compreender é sempre o processo de fusão destes horizontes presumivelmente dados por si mesmos. (ibidem, p. 404, sem grifos no original).

Estruturando estes conceitos, Gadamer narra que a interpretação dos textos é um movimento circular de compreensão, um vai e vem pelos textos e quando a compreensão se realiza esta circularidade é suspensa.

Neste espectro de conceitos ontológicos que Gadamer nos traz a posição de como o este círculo hermenêutico da compreensão se relaciona com os elementos hermenêuticos, nestes termos (grifamos):

(...) A teoria tradicional do "circulo hermenêutico", em particular, se apresenta sob novo aspecto e adquire importância fundamental. Não se trata somente da relação formal entre a antecipação do todo e a construção das partes, correspondente à regra de "decompor e recompor" que nos era ensinada nos cursos de latim - relação que de fato constitui a estrutura circular da compreensão de textos. Ora, o circulo hermenêutico é um circulo rico em conteúdo (inhaltlich erfüllt) que reúne o intérprete e seu texto numa unidade interior a uma totalidade em movimento 
(processual whole). A compreensão implica sempre uma pré-comprensão que, por sua vez, é prefigurada por uma tradição determinada em que vive o intérprete e que modela os seus preconceitos. (GADAMER, 2006, p. 13)

Gadamer defende que este mecanismo não é meramente formal (2014, p. 388), ele é ontológico e existencial no intérprete. Ele refuta qualquer método mecânico de interpretação como algo idôneo para a interpretação, tanto que para ele onde há verdade não há método (ibidem, p. 385) Alias, o titulo da sua obra maior seria melhor, conforme destaca Ernildo Stein (1987, p. 113), como "Verdade ou Método".

Portanto, a teoria hermenêutica-filosófica gadameriana nos traz um paradigma de análise: compreender, interpretar e aplicar é uma ato único, este ir e vir no texto e contexto é denominado por Gadamer de circulo hermenêutico.

No entanto, não se pode colocar em Gadamer o fardo para a solução de toda hermenêutica jurídica. Ele mesmo revelou a Friedrich Muller que a sua hermenêutica até poderia reconhecer o trabalho modelar da operação jurídica, no entanto não estaria ela em condições de desenvolver nortes metodológicos para o Direito e para a Ciência Jurídica (MIOZZO, 2014, p. 13, prefacio de Friedrich Muller). Müller defende que a sua Teoria Estruturante começou onde Gadamer parou com a sua obra "Estrutura da Norma e normatividade" transcendendo a hermenêutica a uma concepção abrangente que inclui a dogmática jurídica metódica, a teoria do direito, a teoria da constituição e teoria jurídica (ibidem, p. 13).

Quanto a esta insuficiência na hermenêutica-filosófica de Gadamer se desenvolveu uma antiga polemica entre a hermenêutica de Gadamer e a dialética de Jürgen Habermas.

Logo que Gadamer lançou Verdade e Método em 1960, Habermas publica em 1967 A Lógica das Ciências Sócias onde examina a hermenêutica gadameriana e lança a sua crítica. Gadamer respondeu a Habermas em outras obras, que por sua vez também replicou em outros escritos inaugurando umas das polemicas mais produtivas e conhecidas no ramo da interpretação jurídica.

Habermas defende que a reflexão, captada pelo pensamento crítico dialético, tem força para quebrar a extensão ontológica gadameriana do preconceito legitimado na tradição. Ele não nega a verdade existencial destes elementos hermenêuticos, muito pelo contrario ele as confirma, no entanto defende que a pretensão de univernalidade da hermenêutica não se confirmou. Assim refletiu Habermas (2009, p. 261):

O preconceito gadameriano em favor do direito dos preconceitos legitimados pela tradição contesta a força da reflexão, que se confirma no fato também de poder recusar a pretensão das tradições. A substancialidade desaparece na reflexão, 


\begin{abstract}
porque esta reflexão não apenas confirma, mas também quebra forças dogmáticas. Autoridade e conhecimento não convergem. Com certeza, conhecimento esta enraizado numa tradição fática; ele permanece ligado a condições contigentes. Todavia, não é sem deixar rastros que reflexão trabalha a facticidade das normas transmitidas. Ela está condenada a ulterioridade. No entanto, retrospectivamente, ela desenvolve uma força retroativa. Nós só podemos nos curvar sobre normas interiorizadas, depois de termos apredido a segui-las de início de maneira cega sob a força exteriormente imposta. Uma vez que a reflexão se lembra do caminho da autoridade, no qual as gramáticas dos jogos de linguagem foram dogmaticamente postas em funcionamento como regras da concepção de mundo e do agir, pode ser eliminado da autoridade aquilo que nela era mero domínio e dissolvido na compulsão desprovida de violência da intelecção e da decisão racional.
\end{abstract}

Como destaca Ernildo Stein (ibidem, p. 114) para Habermas o que falta à hermenêutica filosófica é esta reflexão. A crítica que Habermas faz a Gadamer incide particularmente ali onde este identifica autoridade (tradição) com conhecimento e tenta reabilitar o preconceito a partir da esturura pré-conceitual do compreender.

Apesar de simbolicamente ser uma polemica, compartilhamos com Stein (ibidem, p. 102) que a teoria hermenêutica e o método critico-dialético se complementam. Trata-se de um confronto que esta no plano da complementaridade, apesar da pretensão de universalidade apresentada tanto pela crítica como pela hermenêutica.

A teoria de Gadamer não quer apresentar um método hermenêutico com base numa tecnologia da compreensão, não quer construir um método da compreensão (STEIN, 1987, p. 113). Gadamer nunca teve pretensões de construir uma prescrição mas sim uma teoria descritiva, em sua obra isso é muito claro: "Minha verdadeira intenção, porem, foi e continua sendo uma intensão filosófica: O que está em questão não é o que fazemos, o que deveríamos fazer, mas o que nos acontece alem do querer e fazer (GADAMER, 2014, p. 14). Diferente de Habermas, que numa teoria prescritiva defende que através do processo reflexivo da dialética comunicativa entre os interlocutores pode-se afastar a autoridade da tradição e se chegar no conhecimento.

Entendemos, portanto, que a incompletude para a ciência jurídica na teoria (descritiva) hermenêutica de Gadamer está no fato da ausência de uma (prescrição) dialética reflexiva. Gadamer ao afirmar que quando a compreensão se completa e assim o circulo hermenêutico encerra, descarta o diálogo externo que se deve ter com os demais interlocutores que compartilham o texto e o contexto. Entendemos que isso é essencial quando se trata de texto jurídicos, onde o destinatário da norma não é o único intérprete ${ }^{7}$, pois

\footnotetext{
7 Dentro de uma tópica constitucional subjetiva, segundo Peter Haberle a teoria da interpretação constitucional tem concentrado seus esforços em dois pontos principais: (1) a questão acerca das tarefas e objetivos da interpretação, e (2) a questão acerca dos métodos, que envolve o processo da interpretação e suas regras. No
} 
ao fim e ao cabo, prevalecerá a interpretação do órgão jurisdicional. Se o órgão jurisdicional interpreta determinado texto, logo já esta aplicando, sem ouvir os demais sujeitos do processo e suas respectivas interpretações, ele perde o oportunidade - e o dever - de se chegar numa hermenêutica mais adequada e democrática ao caso concreto e, assim, diminuir a potencialidade do justo. Talvez esta seja a carência em sua teoria que Gadamer narrou a Muller, e que coube a Habermas complementar.

Portanto, defendemos uma hermenêutica reflexiva que é exatamente a descrição ontológica gadameriana do intérprete complementada pela prescrição dialética habermasiana, mormente no Direito Ambiental onde possui grande peso multidisciplinar.

\section{O PAPEL DO JUIZ NA TRADIÇÃO DE ALgUMAS CORRENTES DO DIREITO}

Após contextualizar a descrição gadameriana dentro da ontologia da interpretação e a necessidade prescritiva de uma reflexão nos termos de Junger Habermas, mister trazer um panorama dentro da tradição jurídica a justificação teórica das decisões judiciais do direito para após analisarmos o caso concreto sobre a queima da cana de açúcar no Superior Tribunal de Justiça.

É uma preocupação constante na teoria do direito a necessidade de perceber na interpretação/aplicação a possibilidade de se fazer justiça sócio-ambiental. Quando o intérprete está realmente extraindo um sentido possível do texto ou está criando norma nova a partir do texto posto pelo legislador e a legitimidade desta decisão. A questão está em saber se decisões judiciais a depender das correntes aqui enfrentadas podem ser consideradas justas e efetivadoras de direito e verificar inclusive o nível democrático do intérprete.

Esta atenção da teoria do direito é dada desde o século passado e surgiram, assim, varias correntes doutrinarias em diversos países para delimitar esta fronteira bem como outras que consideram esta separação supérflua.

entanto, há um aspecto fundamental para o qual não se tem dado a devida importância: a questão relativa aos participantes da interpretação. Isto ocorre em razão do forte vínculo que a teoria da interpretação constitucional tem mantido com um modelo de sociedade fechada, conferindo especial destaque aos procedimentos formalizados e à interpretação constitucional realizada pelos magistrados. Contudo, por mais importante que seja a interpretação constitucional dos juízes, ela não é a única possível. HABERLE. Peter. A sociedade aberta dos intérpretes da Constituição: contribuição para a interpretação pluralista e "procedimental" da Constituição. Tradução Gilmar Ferreira Mendes. Porto Alegre: S. A. Fabris, 1997, passim. 
Alguns autores tentaram enfrentar o problema se utilizando inclusive de outros ramos da ciência para justificar as suas teses. Analisaremos algumas tradições jurídicas que foram profícuas nesta analise e contribuíram para tanto.

\subsection{A Escola Histórica do Direito e a Jurisprudência dos Conceitos}

Dentro da Escola Histórica do Direito de Savigny (1779-1881) o juiz tinha um papel meramente o passivo no direito, a tarefa de realizar justiça era afeta funcionalmente ao legislador e não ao juiz, sendo inclusive proibido ao tribunal o uso de uma interpretação teleológica, no ponto segundo Karl Larenz (1969, p. 3):

(...) condena Savigny uma interpretação "teleológica": o juiz deve atender não ao que o legislador busca atingir, mas só ao que na realidade preceituou; ou mais precisamente: ao que nas palavras da lei, segundo o seu sentido lógico, gramatical e a extrair da articulação do sistema, verdadeiramente encontrou uma expressão como conteúdo do seu dispositivo. O juiz não tem, como um criador, que aperfeiçoar a lei - tem apenas que executa-la: 'um acabamento da lei é, decerto, possível, mas deve ser obra unicamente do legislador, em nenhum caso do julgador.

Houve um avanço com a Jurisprudência dos conceitos de Puchta, um dos representantes desta corrente, no século XIX. Surge a possibilidade do juiz suprir as lacunas dos textos legais através de conceitos dispostos numa pirâmide conceitual dentro de um sistema lógico-formal. No ápice desta pirâmide estaria um conceito supremo que procederia da filosofia. Karl Larenz destaca que (ibidem, p.15)

\footnotetext{
Como exemplo desta "escalada conceitual" apresenta ele o conceito de servidão de passagem, que, num primeiro plano, será um direito subjetivo, e, "por conseguinte um poder sobre um objeto"; num segundo plano, um direito "sobre uma coisa", ou como diríamos, um direito real; depois "um direito sobre coisa alheia", e por conseguinte, uma sujeição parcial desta ultima; noutro plano ainda, como a particular espécie desta sujeição a é a fruição, dir-se-á que a servidão de passagem pertence ao gênero dos direitos sobre as coisas para fruição. (...) "genealogia dos conceitos“ ensina, portanto, que o conceito supremo, de que deduzem todos os outros determina pelo seu conteúdo. Porém, de onde procede o conteúdo desse conceito supremo? Segundo PUCHTA, esse conceito procede da filosofia do direito: assim se consegue um ponto de partida seguro com que construir dedutivamente todo o sistema e extrair novas proposições jurídicas.
}

Pela analise da posição teórica de Puchta verifica-se um maior poder do juiz no manuseio do conteúdo do texto, no entanto este conteúdo lhe é dado previamente pela ciência jurídica e pela filosofia do direito. Ou seja, o conceito autorizado na jurisprudência dos 
conceitos é o conceito doutrinário, não judicial. Portanto o que vai realizar justiça direito propriamente dita, além da lei no pensamento de Puchta, é a doutrina jurídica.

\subsection{O Movimento para o Direito Livre, a Jurisprudência dos Interesse e a Jurisprudência dos Valores}

Em reposta a completude do sistema jurídico proposto pela Escola Histórica do Direito e pela Jurisprudência dos Conceitos e o papel passivo do juiz nestas tradições surge a tradição Movimento para o Direito Livre, que teve em Eugen Ehrlich seu principal fundador. Este movimento trouxe um voluntarismo para a decisão judicial até hoje sem precedentes. Traz este movimento descritivamente que inexoravelmente toda decisão judicial é uma atividade criativa e pessoal (ibidem, p. 69-70) que escapa ao método de investigação dos fatos legislativos proposta pela Jurisprudência dos Interesses como veremos infra. A expressão "Movimento para o direito Livre" remonta a uma antiga conferencia de Ehrlich de 1903 que traduz a importância da livre investigação do Direito pela jurisprudência, não através da discricionariedade judicial e emocional, mas a busca da justiça com base na tradição jurídica (ibidem, p. 69). Esta dimensão prescritiva dada por este movimento traz um limite a esta atividade criativa: não pode o juiz nesta atividade fugir a tradição jurídica traduzida pela decisão jurídica dos cidadãos, pela jurisprudência e ciência do direito. Logo, pode-se dizer que o juiz ao aplicar o texto tem poder de criar o direito e realizar a justiça mas esta liberdade possui como limite material a tradição da sua comunidade que pode ser no sentido gadameriano anteriormente já descrito.

Através da Jurisprudência dos Interesses, surgida no inicio do século XX, que teve em Philip Heck seu principal nome - um dissidente do movimento para o direito livre pois se opunha a possibilidade interpretação contra legem defendida por alguns teóricos nesta corrente (MIOZZO, 2014, p. 159) -, houve mais uma reação ao formalismo e ao dogma da completude do direito proposto pela Jurisprudência dos Conceitos. Surge um juiz que deve se atentar aos interesses sopesados pelo legislador ao elaborar a lei pois, afinal, o legislador não tinha a capacidade de solucionar textualmente as necessidades da vida na sua inteiridade. Assim o juiz, através do método da ponderação dos interesses (ibidem, p. 171), assume um papel mais ativo buscando no elemento histórico do texto, através dos trabalhos preparatórios legislativos, a solução e justiça para o caso, conforme destaca Larenz (1969, p. 55): 
(...) O objectivo final da jurisdição e da resolução pelo juiz dos casos concretos é, por seu turno, "a satiasfaçao das necessidades da vida, a satisfação das apetências e das tendências apetivas, quer materiais quer ideais, presentes na comunidade juridicas“. São estas apetências e tendências apetivas" que designamos - elucida Heck - por interesses, e a particularidade da jurisprudência dos interesses consiste em "tentar não perder de vista esse objetivo ultimo em toda a operação, em toda a formação de conceitos".

A jurisprudência dos interesses de Heck conseguiu um inusitado êxito pelo menos no âmbito do âmbito do direito privado (LARENZ, 1997, p. 163). No entanto seus próprios partidários a criticavam pois pecava em limitar o "interesse" no critério definido pelo legislador, e era necessário buscar o que o interesse representava ou deveria representar para as partes do litígio. Surge, assim, com a Jurisprudência dos Valores, uma variação da jurisprudência dos interesses, através de uma aproximação do direito com a sociologia. O elemento histórico da interpretação perde importância com esta variante teórica, separando "interesse" e valoração que seria, em ultima analise, corolário de justiça (ibidem, p. 163). A jurisprudência dos valores, que teve como expoente Harry Westermann, tinha no critério de justiça e na sua respectiva fundamentação jurídica para seus críticos o seu "calcanhar de Aquiles". Ao se relacionar com o conceito de valor que deveria ser o esperado pelas partes, desloca o foco da fundamentação jurídica para uma motivação que prima o problema em detrimento da norma como metodologicamente trabalhou Theodor Viegh em sua obra "Topik

und Jurisprudenz" ${ }^{\prime 8}$. Neste sentido, Karl Larenz (ibidem, p. 170) destaca:

\begin{abstract}
Colocada a questão de como seria susceptível de fundamentação a afirmação de que precisamente tal decisão seria no caso vertente a decisão "justa", deparamos de novo com a questão de se os valores e o que é valioso são, em termos gerais, susceptível de reconhecimento em sentido racional. Igualmente, quando se sustente que é possível produzir algumas asserções fundamentadas sobre aquilo que são os ditames da "justiça", se bem que dessas asserções se não induza qualquer caminho directo para o seu reconhecimento, aquilo que requer a justiça face a determinado caso consubstancia um juízo "justo". Aqui surge a "tópica", cuja pretensão de aplicabilidade à Jurisprudência foi levada a cabo por VIEHWEG ou, de um modo mais amplo, o procedimento de um discurso vinculado ao caso, o tratamento englobante dos problemas emergentes no caso com o objectivo de um consenso dos interlocutores, ou em termos gerais mais abstractos, a "aptidão de consenso" da solução proposta em conclusão. Em tal discurso são considerados relevantes os diversos pontos de vista ("topoi") que se mostrem aptos a servir de argumentos pro ou contra a solução ponderada. De entre eles, o argumento sobre as conseqüências ("o que é que ocorreria se fosse adoptada esta ou aquela solução") desempenha um papel de particular importância.
\end{abstract}

\footnotetext{
${ }^{8}$ Tradução brasileira: VIEHWEG, Theodor. Tópica e Jurisprudência. Uma contribuição à investigação dos fundamentos jurídicos-científicos. Tradução da 5. Ed. Alemã, rev. e ampl. Kelly Susane Alflen da Silva. Porto Alegre: Sergio Antonio Fabris, 2008.
} 


\title{
3.3 A Teoria Pura do Direito de Hans Kelsen
}

Com as concepções de que a ciência do direito estava mais voltada para a sociologia jurídica, a tradição reagiu na busca de um direito puro. Foi Hans Kelsen quem se cuidou desta tarefa, Karl Larenz (1969, p. 81) comenta:

\begin{abstract}
A sua "Teoria Pura do Direito" constitui a mais grandiosa tentativa de fundamentação da ciência do direito como Ciência - mantendo-se embora sob o império do conceito positivista desta ultima e sofrendo das respectivas limitações - que o nosso século veio ate hoje conhecer. $\mathrm{O}$ que não obsta acrescentar: assim como a jurisprudência dos interesses é deficiente como teoria, mas foi de grande utilidade pratica, assim a Teoria Pura do Direito atinge um alto nível como teoria, mas do ponto de vista pratico os seus resultados são pobres. (...)
\end{abstract}

Ao perquirir o papel criativo do juiz nesta teoria verifica-se que para Hans Kelsen há um escalonamento normativo hierarquicamente disposto numa pirâmide que dará regularidade jurídica ao ordenamento (KELSEN, 2007, p. 123). No vértice desta pirâmide está a Constituição e descendo até a base terão as leis, decretos (ambos atos gerais) e depois a sentença e o ato administrativo (atos individuais) (ibidem, p. 126). Todo ato cria e aplica o direito, sendo que o maior grau de criação advêm ato mais próximo do vértice e o maior grau de aplicação do mais próximo da base sempre obedecendo a moldura do alto que está acima. Assim explica Hans Kelsen (ibidem, p. 126):

\footnotetext{
A liberdade do legislador, que só esta subordinado à Constituição, submete-se a limitações relativamente fracas; seu poder de criação permanente relativamente grande. A cada grau que desce, a relação entre liberdade e limitação se modifica em favor do segundo termo: a parte da criação aumenta e da livre criação diminui.
}

Para Hans Kelsen dentro da execução da norma superior e criando na norma inferior há um espaço de decisão do interprete dentro da moldura superior. Por ter esta liberdade de criar o direito dentro da moldura, este agir não é meramente cognitivo, mas de volitivo. Há uma discricionariedade política dentro da moldura. A constituição opera-se da aplicação da norma fundamental, que é a única "não produzida através de um acto de vontade mas apenas mentalmente pressuposta" (LARENZ, 1969, p. 93). Todas as possibilidades de produção do direito dentro das molduras superiores estão corretas na teoria pura de Hans Kelsen, não há injustiças dentro das interpretações possíveis (ibidem, p. 94), Hans Kelsen (2013, p. 153) deixa isso muito claro (grifamos):

\footnotetext{
A indagação sobre qual das várias possibilidades na moldura de uma norma é a "justa" é - conforme a exposição - não uma indagação dirigida ao conhecimento do direito positivo, não problema jurídico-teórico mas político-jurídico. A tarefa: obter da lei a sentença judicial justa ou ato administrativo justo, é essencialmente o mesmo
} 
que criar, na moldura da constituição, as leis justas. Assim como da constituição não se pode obter leis justas, através da interpretação, da lei, também não se pode obter sentenças justas através da interpretação.

Foge do presente estudo explorar as críticas e virtudes da "Teoria Pura do Direito" de Hans Kelsen pormenorizadamente, no entanto, é preciso frisar qual o objeto de Hans Kelsen na sua teoria: uma metodologia para conceituar o direito. A maioria das críticas infundadas feita a teoria pura do direito são dentro de uma filtragem interpretativa, o que não foi o seu foco. $\mathrm{O}$ ato de vontade para Kelsen é uma idealidade e como simples ato humano é alheio ao direito, ou seja, não é objeto da ciência jurídica. Isso significa dizer que o Direito não está fundamentado na moral ou em qualquer outra dimensão que não no próprio Direito. O Direito, portanto, regula sua própria produção através da conhecida pirâmide. O que "produz" esse direito - ato legislativo, ato jurisdicional, ato adminstrativo-, é o ato (ideal) de vontade mas ele é alheio a ciência jurídica. Embora Kelsen seja um relativista moral e não acredite em resposta correta, ele não apresentou uma teoria da interpretação, é só uma teoria positivista pra conceituar o Direito e aí ela e seu intento se esgotam.

Portanto, além do legislador, o juiz, assim como o administrador, na Teoria pura do Direito de Hans Kelsen tem o poder de criar o Direito dentro da moldura normativa superior sendo, dentro desta tradição, livre na conformação.

\section{ANALISE DA DIVERGÊNCIA NO STJ SOBRE A (IM)POSSIBILIDADE DO USO DO FOGO PARA A QUEIMA DA CANA-DE-AÇÚCAR}

A Jurisprudência é uma das formas de expressão do direito. Diferente da filosofia do Direito e da Teoria do Direito, que são livres de interesses práticos, e sem desconsiderar as interpendências sistêmicas, a Jurisprudência tem sempre em vista um ordenamento jurídico determinado e uma atividade jurídica prática (LARENZ, 1997, p. 267). Perceber se a decisão judicial do caso ultrapassou os limites do ordenamento cabe às teorias do direito, das quais algumas tradições exemplificamos nos itens anteriores, e a hermenêutica jurídica, cada qual com o seu olhar. O jurista que decide o caso concreto é um ser histórico e, como tal, é condicionado pela tradição jurídica da comunidade que está inserido. Todas as suas pré- comprensões que serão usadas no contexto do caso para extrair a norma do texto estarão na sua fusão de horizontes, isso é inexorável dentro da hermenêutica filosófica de Gadamer que aqui adotamos sem afastar uma reflexão através de uma dialética habermasiana como fator legitimador 
(hermenêutica reflexiva). A fundamentação desta decisão judicial resolutiva do caso concreto, quando idônea, irá compor a tradição e servirá de horizonte passado para futuras decisões formando um circulo virtuoso na tradição da comunidade jurídica. Portanto, mister um olhar para a jurisprudência dentro de uma perspectiva da teoria do direito para filtrar através da ciência o estagio cientifico que o precedente se encontra e, assim, orientar os casos futuros dentro de uma expectativa legitima mormente, na temática aqui apresentada, para fins de efetivação da cidadania ecológica e da justiça sócio-ambiental.

Em que pese a densidade teórica da questão, esta abordagem possui grande interesse prático nos termos de uma justiça sócio-ambiental como veremos no caso analisado a seguir.

O caso em analise aqui trazido será a divergência existente no âmbito das turmas da primeira Seção no Superior Tribunal de Justiça sobre o artigo 27 artigo Código Florestal (Lei $4.771 / 1965)^{9}$ :

Art. 27. É proibido o uso de fogo nas florestas e demais formas de vegetação. Parágrafo único. Se peculiaridades locais ou regionais justificarem o emprego do fogo em práticas agropastoris ou florestais, a permissão será estabelecida em ato do Poder Público, circunscrevendo as áreas e estabelecendo normas de precaução.

A divergência instaurada foi que para a Primeira Turma na expressão "demais formas de vegetação" não consta a cana-de-açucar e na Segunda Turma consta. A divergência se resolveu entre as Turmas, o julgamento pela 1 ${ }^{a}$. Seção nos Embargos de Divergência em

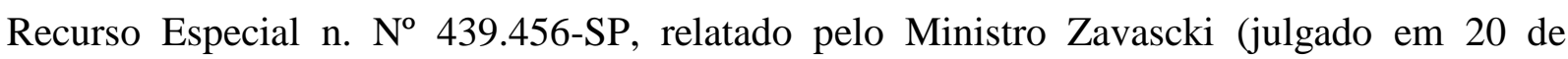
setembro de 2010; DJe: 27/04/2011), ficou estabelecido que a proibição do art. 27 do Código Florestal abrange a cana-de-açúcar, mas que sua queima pode ser realizada mediante prévia autorização (conforme disposição do Dec. 2.661/98), resguardadas exigências constitucionais e legais inerentes à tutela ambiental. Frise-se que, em que pese a aparente solução da divergência, como não há especificações de quais são tais exigências para o licenciamento e resguardado as exigências constitucionais, a controvérsia se manterá.

\footnotetext{
${ }^{9}$ A lei Lei 4.771/1965 foi revogada pela Lei 12.651 e o novo texto na matéria ficou com a seguinte redação: “Art. 38. É proibido o uso de fogo na vegetação, exceto nas seguintes situações: I - em locais ou regiões cujas peculiaridades justifiquem o emprego do fogo em práticas agropastoris ou florestais, mediante prévia aprovação do órgão estadual ambiental competente do Sisnama, para cada imóvel rural ou de forma regionalizada, que estabelecerá os critérios de monitoramento e controle; II - emprego da queima controlada em Unidades de Conservação, em conformidade com o respectivo plano de manejo e mediante prévia aprovação do órgão gestor da Unidade de Conservação, visando ao manejo conservacionista da vegetação nativa, cujas características ecológicas estejam associadas evolutivamente à ocorrência do fogo; III - atividades de pesquisa científica vinculada a projeto de pesquisa devidamente aprovado pelos órgãos competentes e realizada por instituição de pesquisa reconhecida, mediante prévia aprovação do órgão ambiental competente do Sisnama." Como se percebe, o legislador ampliou o rol de exceções para o uso de fogo em vegetação. Em que pese a revogação da lei que embasou o julgamento a presente pesquisa não se esgota nela pois o que esta sendo demonstrado pode ser aplicado em demais casos através de um método dedutivo.
} 
É possível encontrar nos julgados de cada uma das turmas a pré-compresao da temática ambiental e o enquadramento teórico aqui feito.

Em um dos julgados da primeira turma (REsp 294.925/SP Rel. p/ ac. Min. José Delgado, DJ 28/10/2003) assim foi ementado (grifamos):

DIREITO FLORESTAL. AÇÃO CIVIL PÚBLICA. CANA-DE-AÇÚCAR. QUEIMADAS. ARTIGO 21, PARÁGRAFO ÚNICO, DA LEI 4771/65. CÓDIGO FLORESTAL

DECRETO FEDERAL 2661/98. DANO AO MEIO AMBIENTE. INEXISTÊNCIA DE

REGRA EXPRESSA PROIBITIVA DA QUEIMA DA PALHA DA CANA. INVIABILIDADE

DE SUBSTITUIÇÃO DAS QUEIMADAS PELO USO DE TECNOLOGIAS MODERNAS. PREVALÊNCIA DO INTERESSE ECONÔMICO. DECRETO ESTADUAL

AUTORIZA A QUEIMA DA COLHEITA DA CANA. RECURSO DESPROVIDO. 1. O Direito deve ser interpretado $e$ aplicado levando em consideração a realidade sócio-econômico a que visa regulamentar. "In casu", não obstante o dano causado pelas queimadas, este fato deve ser sopesado com o prejuízo econômico e social que advirá com a sua proibição, incluindo-se entre estes o desemprego do trabalhador rural que dela depende para a sua subsistência. Alie-se a estas circunstâncias, a inaplicabilidade de uma tecnologia realmente eficaz que venha a substituir esta prática. 2. Do ponto de vista estritamente legal, não existe proibição expressa do uso do fogo na prática de atividades agropastoris, desde que respeitados os limites fixados em lei. $O$ artigo 27, parágrafo único do Código Florestal proíbe apenas a queimada de florestas e vegetação nativa e não da palha da cana. O Decreto Federal $2.661 / 99$ permite a queima da colheita da cana, de onde se pode concluir que dentro de uma interpretação harmônica das normas legais "aquilo que não está proibido é porque está permitido".

3. Recurso especial improvido.

Diante da passividade gramatical na tutela do meio ambiente, é manifesto o universo do relator, pelo menos neste julgado, com uma pré-compreensão que culmina na vetusta tradição da Escola Histórica do Direito de Savigny, onde sequer motivou o uso de uma interpretação teleológica da norma, o que também era proibido por esta tradição como demonstramos. Poderia-se argumentar que o relator tenha o seu horizonte passado na tradição da teoria pura do direito, no entanto ele não explorou se a lei legislou dentro da moldura constitucional e se o decreto regulamentou dentro da moldura legal.

Outro ponto que merece destaque no aporte teórico aqui relatado, está no voto do ministro Humberto Gomes neste julgado, que ao acompanhar o relator (portanto dentro de uma teoria da Escola Histórica do Direito), disse que "sou neto de usineiro e fui, também, plantador de cana", afirmando ter muita honra de seu passado. Note-se que se tem aqui um exemplo muito claro de fusão de horizontes nos termos de Hans George Gadamer, conforme 
demonstramos, e sua influência na interpretação/aplicação, bem como a necessidade de uma reflexão através do pensamento critico dialético de Junger Habermas, de uma hermenêutica reflexiva. O ministro Humberto Gomes não investiga se as suas opiniões prévias são arbitrarias e muito menos, para depurar esta pré-compreensão, reflete através de um pensamento critico dialético sobre os inúmeros estudos sobre o tema salientando, apenas, o contexto sócioeconômico de uma época passada não analisando a questão ambiental atual.

Quanto à Segunda Turma a fusão de horizonte é outra. No AgRg nos EDcl no REsp n. 1.094.873/SP (DJe: 17/08/2009 rel. Humberto Martins), ao interpretar o parágrafo único do art. 27 do Código Florestal vigente decidiu pela impossibilidade da queima. Assim ficou ementada a decisão (grifamos):

\begin{abstract}
AMBIENTAL - DIREITO FLORESTAL - AÇÃO CIVIL PÚBLICA - CANA- DEAÇÚCAR - QUEIMADAS - ARTIGO 21, PARÁGRAFO ÚNICO, DA LEI N. 4771/65 (CÓDIGO FLORESTAL) E DECRETO FEDERAL N. 2.661/98 - DANO AO MEIO AMBIENTE - EXISTÊNCIA DE REGRA EXPRESSA PROIBITIVA DA QUEIMA DA PALHA DE CANA - EXCEÇÃO EXISTENTE SOMENTE PARA PRESERVAR PECULIARIDADES LOCAIS OU REGIONAIS RELACIONADAS À IDENTIDADE CULTURAL -VIABILIDADE DE SUBSTITUIÇÃO DAS QUEIMADAS PELO USO DE TECNOLOGIAS MODERNAS - PREVALÊNCIA DO INTERESSE ECONÔMICO NO PRESENTE CASO IMPOSSIBILIDADE.

1. Os estudos acadêmicos ilustram que a queima da palha da cana-de-açúcar causa grandes danos ambientais e que, considerando o desenvolvimento sustentado, há instrumentos e tecnologias modernos que podem substituir tal prática sem inviabilizar a atividade econômica.

2. A exceção do parágrafo único do artigo 27 da Lei n. 4.771/65 deve ser interpretada com base nos postulados jurídicos e nos modernos instrumentos de linguística, inclusive com observância - na valoração dos signos (semiótica) - da semântica, da sintaxe e da pragmática.

3. A exceção apresentada (peculiaridades locais ou regionais) tem como objetivo a compatibilização de dois valores protegidos na Constituição Federal/88: o meio ambiente e a cultura (modos de fazer). Assim, a sua interpretação não pode abranger atividades agroindustriais ou agrícolas organizadas, ante a impossibilidade de prevalência do interesse econômico sobre a proteção ambiental quando há formas menos lesivas de exploração. Agravo regimental improvido.
\end{abstract}

É perceptível a diferença da fundamentação na Segunda Turma. Esta ementa demonstra a preocupação no julgado em analisar com base em "estudos acadêmicos" os quais ilustram que a queima da palha da cana-de-açúcar causa grandes danos ambientais e que, ainda, considerando o desenvolvimento sustentado, há instrumentos e tecnologias modernos que podem substituir tal prática sem inviabilizar a atividade econômica efetivando, portanto, uma cidadania ecológica. Ou seja, o relator não se baseou apenas na sua pré-compressão para 
aplicar o texto da norma ${ }^{10}$, buscou refletir com estudos temáticos para, assim, gerar opiniões prévias legitimas para uma adequada fusão de horizontes diante do contexto ambiental e cidadão apresentado.

Percebesse também na ementa a tentativa de compatibilizar dois valores constitucionais, o meio ambiente e a cultura, numa conduta ativa que pode ser classificada como uma "parcialidade positiva" "11. Dentro das tradições aqui expostas, sem esgotar o tema, pois a mesma analise pode ser feita dentro da máxima da proporcionalidade de Robert Alexy ${ }^{12}$ bem como o método da concordância prática de Konrad Hesse ${ }^{13}$, a Segunda Turma se enquadra, dentro das tradições aqui relatadas, na tradição da Jurisprudência dos Valores, buscando nos valores listados na Constituição Federal a sua tópica e o seu corolário de justiça sócio-ambiental. Numa analise mais superficial pode-se dizer que a decisão se enquadra na Jurisprudência dos Interesses, no entanto o elemento histórico, principal critério de justiça nesta tradição, não foi fundamental para se chegar à decisão. Da mesma forma no presente julgado não houve uma incursão no Movimento para o Direito Livre pois, no nosso sentir, o julgado não saiu do programa normativo dos textos jurídicos apresentados.

O que se pode concluir é que no mesmo contexto jurídico é possível se ter uma tutela

10 Para uma diferenciação especifica para a cidadania ecológica entre norma/princípio e norma/regra ver o nosso: AMARAL, Fernando. A distinção entre princípios e regras, a ordem constitucional e a cidadania ecológica: uma proposta doutrinaria. Direito ambiental II [Recurso eletrônico on-line] organização CONPEDI/UFPB; coordenadores: Flavia de Paiva Medeiros de Oliveira, Norma Sueli Padilha, Beatriz Souza Costa. - Florianópolis: CONPEDI, 2014. Página 34-41.

11 A "parcialidade positiva do juiz" (SOUZA, Artur Cézar. A parcialidade positiva do juiz (justiça parcial) como critério de realização - no processo jurisdicional - das promessas do constitucionalismo social. In: VAZ, Paulo Afonso Brum; SAVARIS, José Antonio. (Org.). Direito da previdência e assistência social: elementos para uma compreensão interdisciplinar. Florianópolis: Conselho editorial. Página 329-361) "tem por finalidade a efetivação material dos princípios fundamentais previstos na Constituição Federal. (p. 352). Afinal [...] Se é dever da República a construção de uma sociedade mais justa, solidária, erradicando-se a pobreza e as desigualdades sociais, e sendo a atividade jurisdicional uma atividade proveniente da República Federativa do Brasil, não há dúvida de que a realização desses fins e a execução dessas tarefas também hão de ser desenvolvidas no âmbito do processo civil ou penal. [...] (p. 353)

12 Segundo Robert Alexy: "A máxima da proporcionalidade em sentido estrito decorre do fato de serem os princípios mandamentos de otimização em face das possibilidades jurídicas. Já as máximas da adequação e da necessidade decorrem da natureza dos princípios como mandamentos de otimização em face das possibilidades fáticas". (ALEXY, Robert. Teoria dos direitos fundamentais. Tradução de Virgílio Afonso da Silva, São Paulo: Malheiros Editores, 2014. pp. 117 e 118).

13 Segundo Canotilho (1993. p. 226-228), desenvolvidos a partir do método hermenêutico-concretizador de Konrad Hesse se desenvolve vários princípios e regras interpretativas das normas constitucionais, entre eles a concordância prática ou da harmonização que tem como núcleo essencial a exigência de ponderação dos bens jurídicos em conflito de forma a evitar o sacrifício total de uns em relação aos outros. CANOTILHO, José Joaquim Gomes. Direito Constitucional e Teoria da Constituição. 6. ed. Revista. Coimbra (Portugal): Livraria Almedina, 1993. pp. 226-228). 
maior o menor tutela do bem jurídico - ambiental, no caso trazido - a depender dos preconceitos do intérprete bem como a da ausência de um procedimento reflexivo sobre o tema. Ainda, é possível identificar na fundamentação da decisão determinadas tradições que não mais se coadunam com a força normativa da Constituição mormente se ausente uma hermenêutica reflexiva.

\section{CONCLUSÃO}

Verificou-se com o presente estudo que o poder do juiz variou horizontalmente o seu espaço em aplicar o direito. Num primeiro momento constatou-se que dentro da filosofia hermenêutica de Gadamer não existe uma cisão ontológica entre compreender, interpretar e aplicar. Estes atos são únicos, na tradição gadameriana, que sofrem uma forte influencia dos preconceitos do interprete com base na autoridade da tradição. Posteriormente verificou-se que a "polemica" Gadamer/Habermas é mais inclusiva do que excludente para uma adequada inclusão da hermenêutica filosófica na interpretação jurídica. Chegou-se a uma expressão que, no atual estagio desta pesquisa se designou como hermenêutica reflexiva que é exatamente esta que é exatamente a descrição ontológica gadameriana do intérprete complementada pela prescrição dialética habermasiana.

Demonstrou-se que a depender da tradição jurídica manejada pelo julgado é possível verificar um maior ou menor grau de tutela do bem jurídico ambiental, bem como a realização da justiça sócio-ambiental no caso concreto para evitar a incidência da proibição da proteção deficiente. Dentro da Escola Histórica do Direito de Savigny o juiz tinha um papel meramente o passivo no direito, a tarefa de criação do direito era afeta funcionalmente ao legislador e não ao juiz, sendo inclusive proibido ao tribunal o uso de uma interpretação teleológica, logo esta tradição não serve ao direito moderno como se demonstrou no estudo de caso ambiental. Com a Jurisprudência dos conceitos de Puchta do século XIX, surge a possibilidade do juiz suprir as lacunas dos textos legais através de conceitos dispostos numa pirâmide conceitual dentro de um sistema lógico-formal (no ápice desta pirâmide estaria um conceito supremo que procederia da filosofia). Em reação a pretensa completude do direito proposto pela Jurisprudência dos conceitos surge a tradição Movimento para o Direito Livre de Eugen Ehrlich, a qual trouxe trouxe o voluntarismo para a decisão judicial, autorizando o juiz uma livre investigação do Direito e da justiça com limite na tradição jurídica de uma comunidade. Através da Jurisprudência dos Interesses de Philip Heck houve também houve 
uma reação ao formalismo e ao dogma da completude do direito proposto pela Jurisprudência dos Conceitos, advogando para a postura de um juiz que deve se atentar aos interesses ponderados pelo legislador quando elaborou as a lei, sendo a variante Jurisprudência dos Valores advogando que a ponderação deve ser feita entre os valores esperado pelas partes. Com as concepções de que a ciência do direito estava mais voltada para a sociologia jurídica, filosofia e ha uma tradição jurídica difusa Kelsen reagiu na busca de um direito puro que o juiz na sua teoria pura do direito o poder de criar o direito dentro da moldura legal.

Com o estudo de caso apresentado sobre a (impossibilidade) da queima de cana-deaçúcar na jurisprudência do Superior Tribunal de Justiça verificou-se que a ausência de uma reflexão pode conduzir hermeneuticamente a uma literalidade do texto legal que não se coaduna com os valores apresentados na Constituição Federal, como se deu na Primeira Turma resultado completamente oposto da Segunda Turma.

O resultado alcançado foi a verificação da influencia da pré-comprensão e da necessidade de uma compreensão reflexiva do juiz na aplicação da norma conduzindo-o, com esta conduta, a uma justiça sócio-ambiental e uma tutela mais abrangente da cidadania ecológica do bem jurídico ambiental, concluindo que os preconceitos e a reflexão sobre o contexto normativo apresentado são fundamentais para se diminuir os danos ambientais consubstanciando uma hermenêutica reflexiva a qual numa perspectiva inclusiva da hermenêutica gadameriana e da dialética habermasiana como legimadoras de uma teoria jurídica emancipadora.

\section{REFERÊNCIAS}

ACSELRAD, Henri; MELLO, Cecília Campello do Amaral; BEZERRA, Gustavo das Neves. O que é Justiça Ambiental. Rio de Janeiro: Garamond, 2009.

ALEXY, Robert. Teoria dos direitos fundamentais. Tradução de Virgílio Afonso da Silva, São Paulo: Malheiros Editores, 2014.

AMARAL, Fernando. A distinção entre princípios e regras, a ordem constitucional e a cidadania ecológica: uma proposta doutrinaria. Direito ambiental II [Recurso eletrônico on-line] organização CONPEDI/UFPB; coordenadores: Flavia de Paiva Medeiros de Oliveira, Norma Sueli Padilha, Beatriz Souza Costa. - Florianópolis: CONPEDI, 2014. Página 34-41. 
BOBBIO, Norberto. A era dos direitos. tradução de Carlos Nelson Coutinho, Rio de Janeiro: Elsevier, 2004.

BIRNFELD, Carlos André. Cidadania Ecológica. Pelotas: Delfos, 2006.

BIRNFELD. Liane Francisca Hüning. A extrafiscalidade nos impostos brasileiros como instrumento jurídico-econômico de defesa do meio ambiente ecologicamente equilibrado 2013. 299 f. Tese (Doutorado) - Faculdade de Direito, Pontifícia Universidade Católica do Rio Grando (sic) Sul, Porto Alegre, 2013.

CANOTILHO, José Joaquim Gomes. Direito Constitucional e Teoria da Constituição. 6. ed. Revista. Coimbra (Portugal): Livraria Almedina, 1993.

GADAMER, Hans-Georg. Verdade e Método. Tradução de Flávio Paulo Meurer; revisão da traduçao de Enio Pailo Giachini. 14. ed.. Petrópolis: Vozes, Bragança Paulista: Editora Universitária São Francisco, 2014.

O problema da consciência histórica. Organizador: Pierre Fruchon. Tradução: Paulo Cesar Duque Estrada. 3 ed. Rio de Janeiro: FGV, 2006.

HABERLE. Peter. A sociedade aberta dos intérpretes da Constituição: contribuição para a interpretação pluralista e "procedimental” da Constituição. Tradução de Gilmar Ferreira Mendes. Porto Alegre: S. A. Fabris, 1997.

HABERMAS, Junger. A lógica das ciências sociais. Tradução de Marco Antonio Casanova. Petrópolis: Vozes, 2009.

KELSEN, Hans. Jurisdição Constitucional. Tradução do alemão: Alexandre Krug, Tradução do italiano: Eduardo Brandão, Tradução do Frances: Maria Ermatina de Almeida Prado Galvão. 2 ed. São Paulo: Martins Fontes, 2007.

Teoria pura do direito. Tradução de J. Cretella Jr. E Agnes Cretela. - 9 ed. rev. São Paulo: Revista dos Tribunais, 2013. 
LARENZ, Karl. Metodologia da Ciencia do Direito. Tradução de José de Sousa e Brito e José António Veloso. 2 ed. Lisboa: Fundação Calouste Gulbenkian, 1969.

Metodologia da Ciencia do Direito. Tradução de José Lamego. 3 ed. Lisboa: Fundação Calouste Gulbenkian, 1997.

LEITE, José Rubens Morato. AYALA, Patryck de Araújo. Dano ambiental: do individual ao coletivo extrapatrimonial. Teoria e prática. 6. ed. São Paulo: Revista dos Tribunais, 2014.

LOBATO, Anderson Orestes Cavalcante. O reconhecimento e as garantias constitucionais dos direitos fundamentais. Cadernos de Direito Constitucional e Ciência Política. São Paulo: Ed. RT, n. 22, p. 141-159, 1998.

MARSHAL, T. H. Cidadania, classe social e status. Trad. Meton Porto Gadelha. Rio de Janeiro: Zahar, 1967.

MIOZZO, Pablo. Interpretação Jurídica e criação judicial do Direito: De Savigny a Friedrich Müller. Curitiba: Juruá. 2014.

SOUZA, Artur Cézar. A parcialidade positiva do juiz (justiça parcial) como critério de realização - no processo jurisdicional - das promessas do constitucionalismo social. In: VAZ, Paulo Afonso Brum; SAVARIS, José Antonio. (Org.). Direito da previdência e assistência social: elementos para uma compreensão interdisciplinar. Florianópolis: Conselho editorial. Página 329-361.

STEIN, Ernildo. Dialética e hermenêutica: Uma controvérsia sobre método e filosofia. In: HABERMAS, Jürgen. Dialética e Hermenêutica: para a crítica da hermenêutica de Gadamer. Tradução: Álvaro L.M. Valls. Porto Alegre: L\&PM, 1987. 